Research Article

\title{
Study of a Conformational Equilibrium of Lisinopril by HPLC, NMR, and DFT
}

\author{
Sondes Bouabdallah, ${ }^{1}$ Med Thaieb Ben Dhia, ${ }^{2}$ and Med Rida Driss ${ }^{1}$ \\ ${ }^{1}$ Laboratoire de Chimie Analytique Appliquée, Faculté des Sciences de Bizerte, 7021 Zarzouna, Tunisia \\ ${ }^{2}$ Laboratoire de Chimie Organique Structurale, Synthèse et Etude Physico-Chimique (Equipe de Chimie de Coordination), \\ Faculté des Sciences de Tunis, 1060 Tunis, Tunisia
}

Correspondence should be addressed to Sondes Bouabdallah; sondes.bouabdallah@laposte.net

Received 31 July 2013; Accepted 18 October 2013; Published 25 February 2014

Academic Editor: Richard G. Brereton

Copyright (C) 2014 Sondes Bouabdallah et al. This is an open access article distributed under the Creative Commons Attribution License, which permits unrestricted use, distribution, and reproduction in any medium, provided the original work is properly cited.

\begin{abstract}
The isomerization of lisinopril has been investigated using chromatographic, NMR spectroscopic, and theoretical calculations. The NMR data, particularly the NOEDIFF experiments, show that the major species that was eluted first is the trans form. The proportion was $77 \%$ and $23 \%$ for the trans and cis, respectively. The thermodynamic parameters $(\Delta H, \Delta S$, and $\Delta G)$ were determined by varying the temperature in the NMR experiments. The interpretations of the experimental data were further supported by DFT/B3LYP calculations.
\end{abstract}

\section{Introduction}

Lisinopril, N-(1-carboxy-3-phenylpropyl)-L-lysyl-L-proline, belongs to a class of antihypertensive agents which inhibit the angiotensin-converting enzyme (ACE) to control blood pressure [1]. The active parts of ACE inhibitors are peptide derivatives containing $\mathrm{C}$-terminal proline residues. Like other proline-containing peptides, lisinopril exists as an equilibrium mixture of $c i s$ and trans isomers, with respect to the proline amide bond (Figure 1) [2,3]. Under unstrained conditions most peptide bonds adopt the trans isomeric form, mainly because of the weaker steric repulsion between hydroxyl and carboxyl group effects in the molecule when compared to the cis. The trans form in lisinopril was shown to be the preferred isomer and biologically active [4-6]. The assignment separation of cis and trans form of lisinopril has been carried out by HPLC [5, 7-12], CZE [13-16], and NMR spectroscopy [2,17-22]. The latter technique is a powerful tool and has been widely applied for structural and stereochemical characterization of amino acids, oligo- and polypeptides [23-26]. The cis-trans isomerization of peptide bonds is a slow process on the NMR time scale under normal conditions at ambient temperature due to the high barrier resulting from the $\mathrm{C}-\mathrm{N}$ partial double bond character. NMR spectroscopy has therefore been successfully used to study the cis-trans isomerization process of lisinopril in solution $[25,27]$.

In this paper, we report on the isomerization of lisinopril using a combination of HPLC, NMR spectroscopy, and theoretical approaches. The effect of temperature on the cis-trans isomerization process of lisinopril was investigated in order to determine different thermodynamic parameters $(\Delta H, \Delta S$, and $\Delta G)$.

\section{Experimental}

2.1. Samples. Lisinopril was kindly provided from Solvay Pharmaceuticals.

2.2. Reagents. Potassium dihydrogen phosphate, sodium hydroxide, and phosphoric acid were of RP quality from Prolabo (France). Methanol, acetonitrile, and tetrahydrofuran (THF) were of HPLC grade from LabScan (Dublin, Ireland).

The mobile phase was prepared by first preparing a solution of $0.02 \mathrm{M} \mathrm{KH}_{2} \mathrm{PO}_{4}$, adjusting its $\mathrm{pH}$ to 2 with phosphoric acid and finally mixing the solution with an organic modifier (acetonitrile, methanol, and THF). 


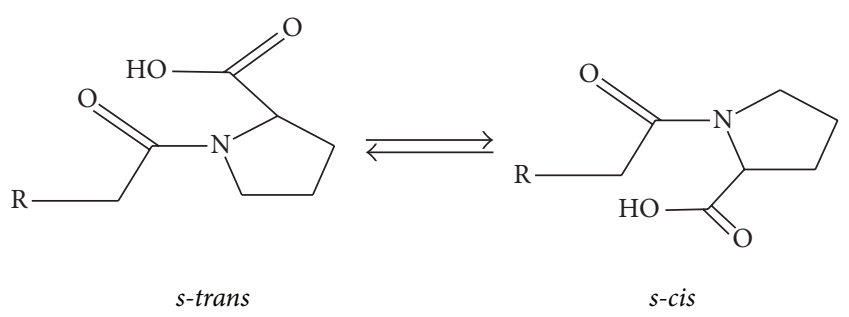

FIGURE 1: Interconversion of L-proline.

The mobile phases were always filtered using $0.45 \mu \mathrm{m}$ membrane filter (Supelco) and degassed by sonication.

2.3. Chromatography. Liquid chromatographic analyses were performed using a Hewlett Packard 1100 HPLC system equipped with a photo diode array UV detector set at $215 \mathrm{~nm}$. Injection was performed using an autoinjector. A Supelco LC $18(5 \mu \mathrm{m})$ column $(250 \times 4.6 \mathrm{~mm}$ I.D) and a guard column $(20 \times 4.6$ I.D) both from Supelco (Bellefonte, PA, USA) were used. The $\mathrm{pH}$ of mobile phase buffers was adjusted by means of a Schott model CG $825 \mathrm{pH}$ meter (Germany).

2.4. Nuclear Magnetic Resonance (NMR Spectroscopy). ${ }^{1} \mathrm{H}$ NMR spectra were obtained at $300.13 \mathrm{MHz}$ on a Bruker Avance III spectrometer. The probe temperature was $298 \mathrm{~K}$. ${ }^{1} \mathrm{H}$ chemical shifts were measured relative to tetramethylsilane [TMS, $\left(\mathrm{CH}_{3}\right)_{4} \mathrm{Si}$ ]. Spectral width was $4201.68 \mathrm{~Hz}$, acquisition time $2.818 \mathrm{~s}$, numbers of scans 120, FID: TD 16384, SI 16384, LB 0.100, and relaxation time was $0.5 \mathrm{~s}$.

All measurements were made on lisinopril in $\mathrm{CD}_{3} \mathrm{CN} / \mathrm{D}_{2} \mathrm{O}$ (1/9) solution. The variable temperature NMR spectra were acquired using the same instrument. Probe temperatures $( \pm 0.5 \mathrm{~K})$ were measured with a calibrated digital thermocouple. Samples were allowed to equilibrate for $10 \mathrm{~min}$ at each temperature before recording the spectrum.

2.5. Computational Details. Density functional theory (DFT) calculations were carried out on the cis and trans isomers of lisinopril with the Gaussian 03W suite of programs [28], with the nonlocal hybrid functional denoted as B3LYP [29]. Then basis sets used were zeta $6-31+G^{*}[30-34]$, doubly polarized with diffuse functions on all the atoms. The geometries of both the cis and trans isomers were optimized using an analytical gradient. The harmonic vibration frequencies of the different stationary points of the potential energy surfaces (PES) have been calculated at the same level of theory in order to identify the local minima as well as to estimate a corresponding zero-point vibrational energy (ZPE).

\section{Results and Discussion}

3.1. HPLC Study. The study of the cis/trans equilibrium of lisinopril by HPLC demonstrates that chromatographic conditions such as flow rate, temperature, $\mathrm{pH}$, and organic modifier have an important effect on peak shape and retention time of lisinopril.
It appears that the separation of the two isomers of lisinopril can be achieved using a mobile phase consisting of a mixture of $20 \mathrm{mM}$ phosphate buffer [pH 7]-acetonitrile $(90 / 10 ; \mathrm{v} / \mathrm{v})$, a column temperature of $279 \mathrm{~K}$, and flow rate of $2 \mathrm{~mL} / \mathrm{min}$ with retention time $t_{R 1}=3.49 \mathrm{~min}$ and $t_{R 2}=$ $4.55 \mathrm{~min}$. However, a higher temperature is required for the elution of lisinopril as a single sharp peak at $2.76 \mathrm{~min}$ (Figure 2).

This is because it was found that an elevated temperature led to deterioration in the separation of the two isomers.

Moreover, at $328 \mathrm{~K}$ lisinopril was eluted as a narrow single peak due to the high isomerization rate of the two isomers. On the other hand, at low temperature the two isomers were resolved almost completely indicating that the interconversion rate had slowed down.

From ambient temperature chromatograms, the isomer trans/cis ratio was integrated to be $76 / 24$. This result is similar to those reported earlier demonstrating that high temperature was useful for elution of proline-containing substances as a single peak $[7,11,35]$. Conversely, a low temperature is known to have a potential effect on the separation of isomers $[5,9,36-39]$.

3.2. NMR Studies. The structure of lisinopril (Figure 3) shows 21 carbon atoms with two sets of two chemically equivalent carbons describing the ortho- and metapositions on the aromatic ring. So, we expect to observe 19 signals in ${ }^{13} \mathrm{C} \mathrm{NMR}$ spectra. However, the obtained spectra showed the doubling of all signals confirming the existence of the two isomers (Figure 4).

In addition, the ${ }^{1} \mathrm{H}$ NMR spectra of lisinopril in $\mathrm{CD}_{3} \mathrm{CN} / \mathrm{D}_{2} \mathrm{O}$ at $298 \mathrm{~K}$ (Figure 5(a)) show two sets of triplets of unequal intensities. The multiplicity of each signal set reflected first from the interaction of $\mathrm{H} 58$ with $\mathrm{H} 25$ and $\mathrm{H} 26$, giving the two signals in the 3.8-4.1 ppm region, and second from the interaction of $\mathrm{H} 43$ with $\mathrm{H} 45$ in the 4.1-4.4 ppm region. The same spectrum recorded at $333 \mathrm{~K}$ (Figure 5(b)) shows a better separation of the two signals at $4.1 \mathrm{ppm}$.

These isomers are assigned to a cis-trans equilibrium of the rotation around the amide bond. As described earlier, it is worth noting that this equilibrium appears to be slow on the NMR time scale at ambient temperatures [37, 40]. Using the area of resonance signals of proton $58(3.8-4.4 \mathrm{ppm})$, the isomer ratio was integrated to be $77 / 23$ at $298 \mathrm{~K}$. The result obtained in a separate experiment recorded at a probe temperature of $298 \mathrm{~K}$ is consistent with that determined by HPLC at the same temperature.

We conclude that the major conformer in the ${ }^{1} \mathrm{H}$ NMR spectrum of lisinopril corresponds to the first eluted peak in the HPLC chromatogram at ambient temperature, which exists in a higher proportion. A similar study demonstrated this correspondence in the case of ramiprilat [4], enalaprilat [5], and perindopril [39] in different solvents.

It is well known that the NOE effect $(\zeta)$ between two dipole-dipole interacting nuclei is inversely proportional to the distance $\left(r_{i j}\right)^{6}$ between the irradiation site $(i)$ and the measured one $(j)$, respectively [41], according to the following formula: $\xi_{i}(s)=f\left(1 / r_{i s}^{6}\right)$. 


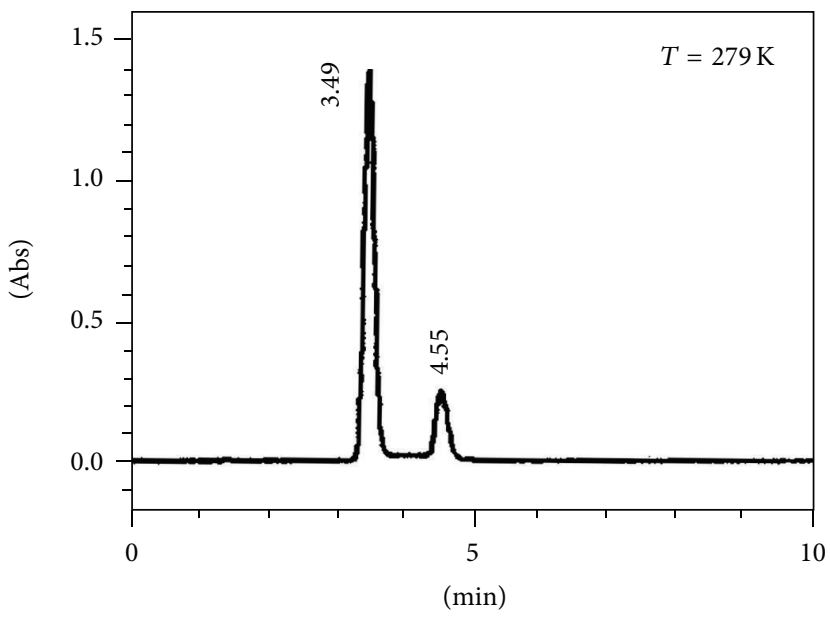

(a)

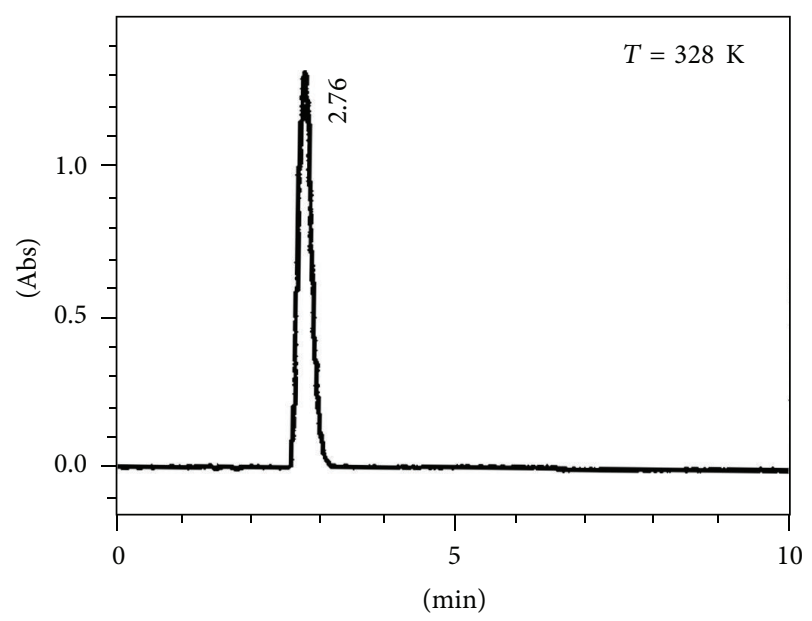

(b)

FIGURE 2: Effect of column temperature on the peak shape of lisinopril; mobile phase: phosphate buffer, [pH 7]/acetonitrile (90: 10, v/v); flow rate: $2.0 \mathrm{~mL} / \mathrm{min}$; stationary phase: Supelco LC18, $5 \mu \mathrm{m}(250 \times 4.6 \mathrm{~mm}$ I.D.). (a) $T=279 \mathrm{~K}$, (b) $T=328 \mathrm{~K}$.

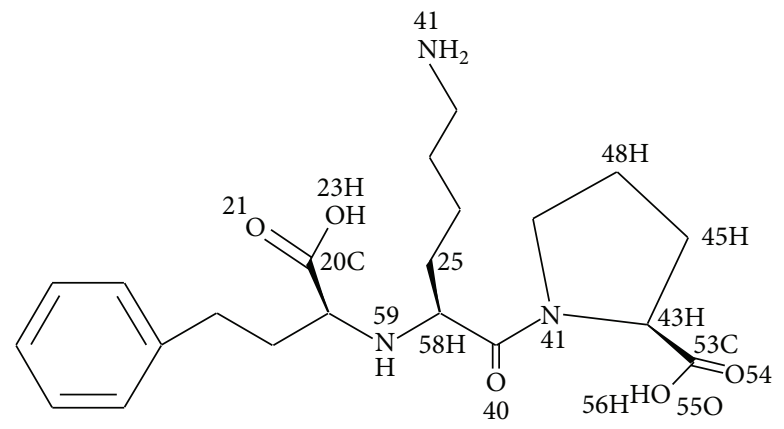

(a)

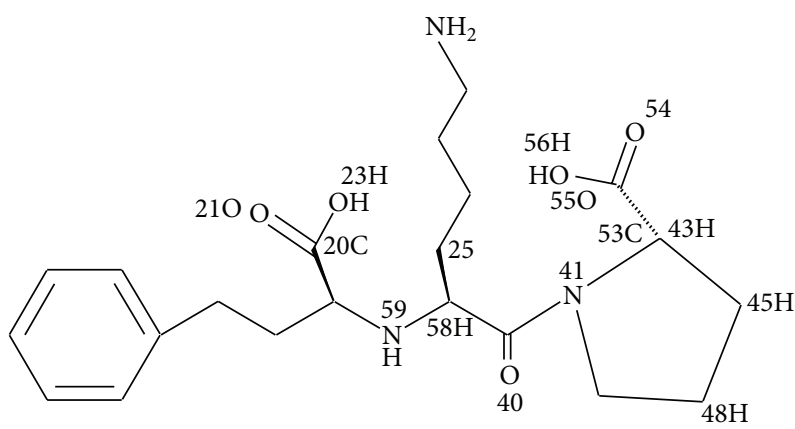

(b)

FIgURE 3: Chemical structure of lisinopril (S, S, S): (a) cis form and (b) trans form.

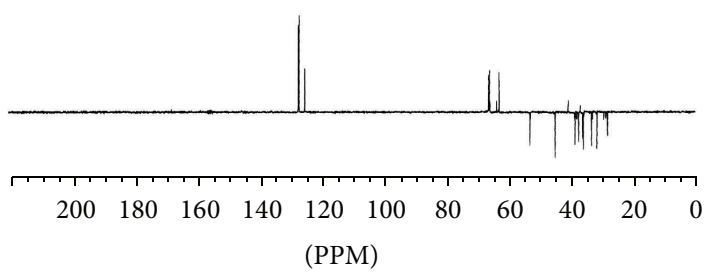

(a)

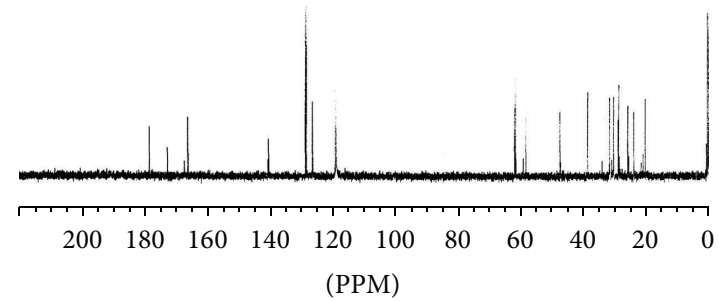

(b)

FIgURE 4: ${ }^{13} \mathrm{C}$ NMR spectrum of lisinopril in $\mathrm{D}_{2} \mathrm{O} / \mathrm{CD}_{3} \mathrm{CN}(9 / 1, \mathrm{v} / \mathrm{v})$. (a) Dep 135t, (b).

Therefore, a low $\operatorname{NOE}(\zeta=8 \%)$ is observed at $\mathrm{H}_{58}(\delta=$ $3.16 \mathrm{ppm})$ when $\mathrm{H}_{43}(\delta=4.35 \mathrm{ppm})$ is irradiated in the major conformer. Accordingly, a stronger $\operatorname{NOE}(\zeta=21 \%)$ is noted at $\mathrm{H}_{58}(\delta=3.7 \mathrm{ppm})$ when $\mathrm{H}_{43}(\delta=3.31 \mathrm{ppm})$ is irradiated in the minor conformer.

In addition, when $\mathrm{H}_{48}(\delta=4.45 \mathrm{ppm})$ is irradiated, we observe at $\mathrm{H}_{58}$ a NOE $(\zeta=34 \%)$ in the major conformer and a $\operatorname{NOE}(\zeta=10 \%)$ in the minor conformer (Figure 6).
This shows that the NOE in the minor conformer for the H43/H58 is more important than the NOE in the major conformer, which implies that in the major conformer, the distance between the nuclei is higher than the one in the minor conformer

$$
\begin{aligned}
& r_{43-58(\mathrm{~min})}<r_{43-58(\mathrm{maj})}, \\
& r_{48-58(\mathrm{maj})}<r_{48-58(\mathrm{~min})} .
\end{aligned}
$$




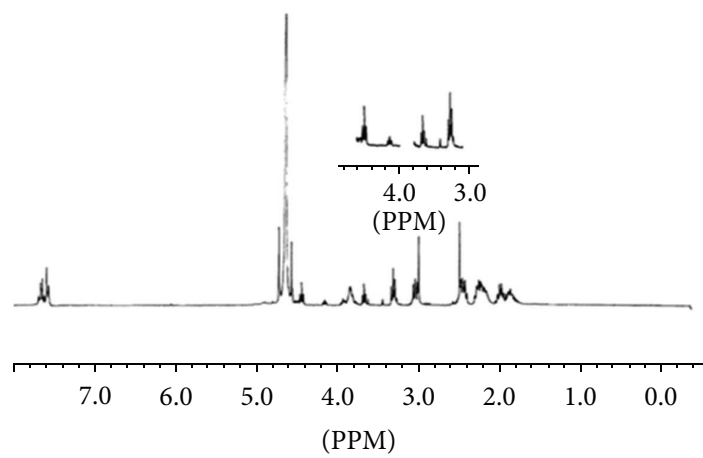

(a)

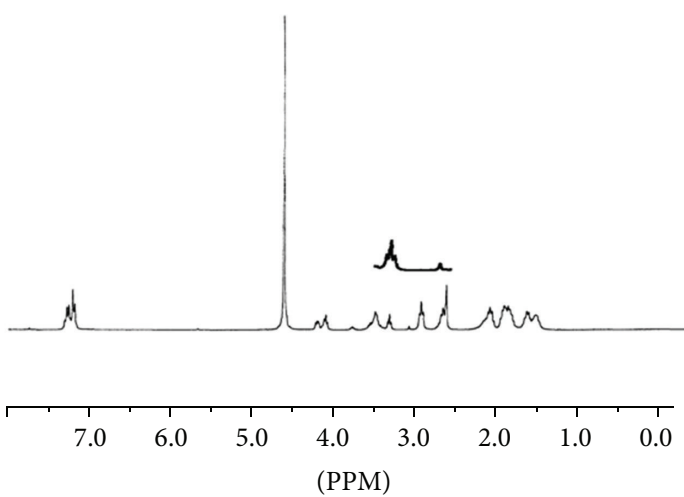

(b)

Figure 5: ${ }^{1} \mathrm{H}$ NMR spectrum of lisinopril in $\mathrm{D}_{2} \mathrm{O} / \mathrm{CD}_{3} \mathrm{CN}(9 / 1, \mathrm{v} / \mathrm{v})$. (a) $\mathrm{T}=298 \mathrm{~K}$, (b) $\mathrm{T}=333 \mathrm{~K}$.

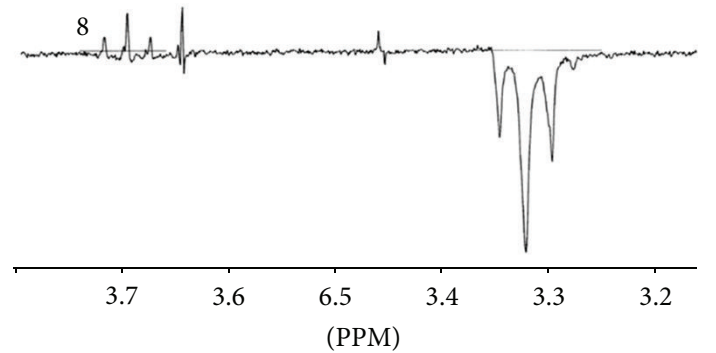

(a)

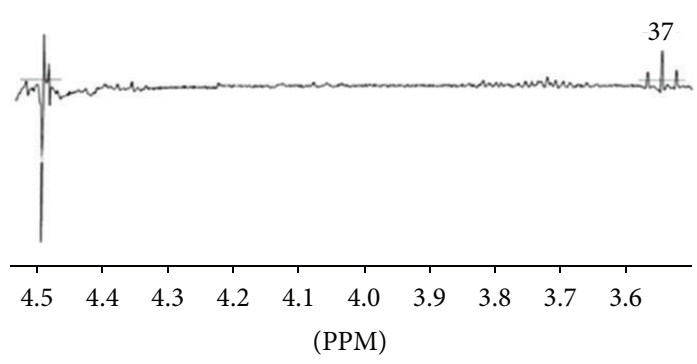

(c)

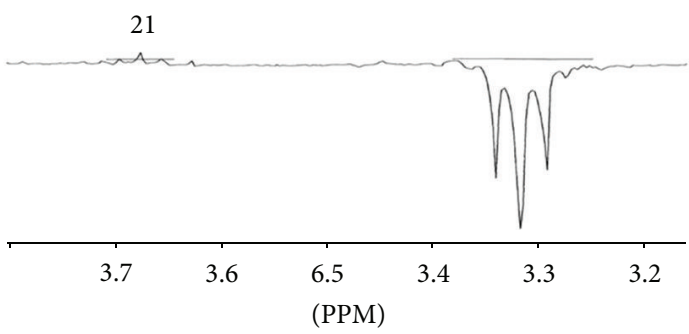

(b)

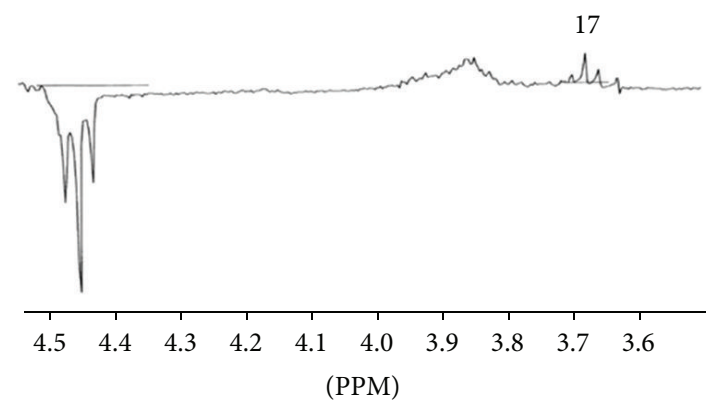

(d)

Figure 6: NOE difference spectra of lisinopril in $\mathrm{D}_{2} \mathrm{O} / \mathrm{CD}_{3} \mathrm{CN}(9 / 1, \mathrm{v} / \mathrm{v})$, at $298 \mathrm{~K}$ and $300 \mathrm{MHz}$. Irradiation of $\mathrm{H} 43$ and $\mathrm{H} 48$ (a, c) major conformer; (b, d) minor conformer. The numbers next to the peaks represent the quantified NOE at H58.

Based on the relationship between NOE and internuclear distances, one can give the expression of distance in each conformer

$$
\begin{aligned}
& \left(r_{43-58}\right)_{\min }=\left(\frac{8}{21}\right)^{1 / 6}\left(r_{43-58}\right)_{\text {maj' }} \\
& \left(r_{48-58}\right)_{\min }=\left(\frac{34}{10}\right)^{1 / 6}\left(r_{48-58}\right)_{\text {maj }} \cdot
\end{aligned}
$$

Consequently, the examination of the molecular structure of each conformer of lisinopril confirmed that the distance $r_{43-58}$ in the cis conformer is indeed smaller than the distance in the trans form. The ${ }^{1} \mathrm{H}$ NMR intensities suggest that the major conformer is the trans form and the minor conformer is the cis form. The nuclei of the s-trans conformer are more deshielded than those of $s$-cis conformer, in agreement with literature results $[41,42]$.

3.3. Thermodynamic Study. At slow chemical exchange, the relative proportion of the two conformers at different temperatures in the range (279-333) $\mathrm{K}$ and the cis/trans equilibrium constant of lisinopril have been measured by relative integrals of the two resonance signals of the two states of isomerizations of lisinopril.

These signals are well resolved and allowed to determine accurately the equilibrium constants for the cis to trans interconversion at different temperatures and to measure the thermodynamic parameters: enthalpy $\left(\Delta H^{\circ}\right)$, entropy $\left(\Delta S^{\circ}\right)$ 


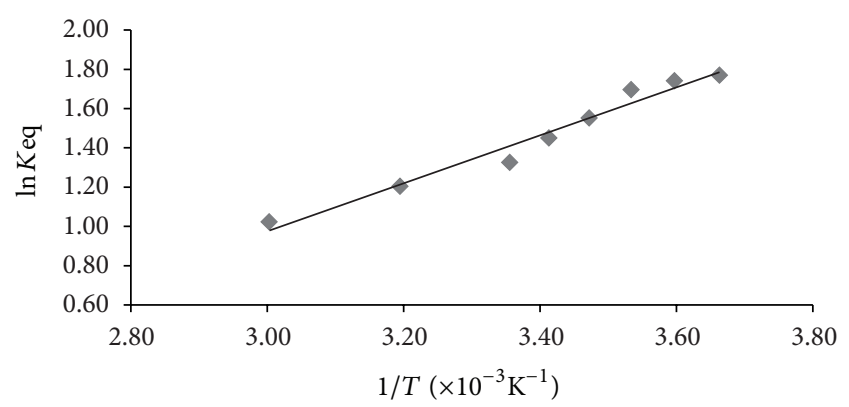

Figure 7: Representative van't Hoff plot in $\mathrm{D}_{2} \mathrm{O} / \mathrm{ACND}_{3}(9 / 1)$.

of the equilibrium on the basis of the van't Hoff equation. The Gibbs free enthalpy $\left(\Delta G^{\circ}\right)$ is deduced at ambient temperature.

The plot of $\ln K$ versus the reciprocal of the absolute temperature is a straight line of equation $\ln K=$ 1212.91/T - 2.6359 (Figure 7). The correlation coefficient for this straight line is $r=0.995$. The enthalpy was obtained via the slope and the entropy via the intercept of plot. The thermodynamic parameters obtained from experiment were $\Delta H^{\circ}=-10.36 \mathrm{~kJ} / \mathrm{mol}, \Delta S^{\circ}=21.91 \mathrm{~J} / \mathrm{k} \cdot \mathrm{mol}$, and $\Delta G_{298 \mathrm{~K}}=$ $-16.91 \mathrm{~kJ} / \mathrm{mol}$.

Remarkably, the equilibrium cis to trans isomerization was enthalpically and entropically favored in this condition. Consequently, the decrease in the temperature expected a displacement of the conformational equilibrium to the $s$ trans conformer. The latter is stabilized by hydrogen bonding between the carbonyl (40) and the hydrogen of hydroxyl group $\mathrm{OH}$ of the acid function (56). This result is in agreement with other studies reported on a similar product such as enalapril [5].

3.4. Theoretical Calculations. In order to confirm the NMR data obtained for the cis/trans isomerization of lisinopril, the geometrics of the two conformers were fully optimized at the DFT/B3LYP level of theory using $6-31++\mathrm{G}^{*}$ basis set. The structures have been identified as local minima on the singlet potential energy surfaces (PES) (Figure 8). Optimized values of selected geometrical parameters are listed in Table 1. The potential energy difference between the two isomers of lisinopril was $11.397 \mathrm{~kJ} / \mathrm{mol}$ indicating the stability of trans over the cis isomer. This difference is in good agreement with experimental data that the trans is the majorities form.

As shown in Table 1, in the trans conformer the interaction between H56-O40 $\left(d_{\mathrm{H} 56-\mathrm{O} 40}=1.717 \AA\right)$ would be stronger than that in the cis $\left(d_{\mathrm{H} 56-\mathrm{O} 40}=3.857 \AA\right)$, thus generating a sharp reduction of the valence angle C53-O55H56 $\theta=103.1^{\circ}$ in the trans form and $\theta=2.3^{\circ}$ in the cis form) and a strong variation on dihedral angle O40-C39C41-C50 ( $\phi=176.6^{\circ}$ in the trans form and $2.6^{\circ}$ in the cis form), indicating possible existence of some hydrogen bond interactions which would be more favored in the trans than in cis isomers.

This stability of trans form over the cis form is further confirmed by the charge density between the same atoms $\left(\Delta q_{s-\text { trans }}=0.08, \Delta q_{s-c i s}=0.02\right)$. The strong interaction
TABLE 1: Selected bond lengths ( $\AA$ ) and angles (deg) for the cis and trans isomer of lisinopril.

\begin{tabular}{|c|c|c|}
\hline Parameter & $s$-cis & s-trans \\
\hline \multicolumn{3}{|c|}{ Lengths } \\
\hline $\mathrm{H} 56-\mathrm{O} 40$ & 3.857 & 1.717 \\
\hline $\mathrm{H} 56-\mathrm{O} 21$ & 1.799 & 4.816 \\
\hline $\mathrm{H} 23-\mathrm{O} 40$ & 3.618 & 4.033 \\
\hline H56-N41 & 2.486 & 2.613 \\
\hline H56-N59 & 2.660 & 4.875 \\
\hline H23-N59 & 3.721 & 3.717 \\
\hline $\mathrm{H} 23-\mathrm{N} 41$ & 4.958 & 4.947 \\
\hline \multicolumn{3}{|c|}{ Bonds lengths } \\
\hline H56-O55 & 0.988 & 0.995 \\
\hline O55-C53 & 1.338 & 1.338 \\
\hline $\mathrm{H} 23-\mathrm{O} 22$ & 0.972 & 0.972 \\
\hline $\mathrm{O} 22-\mathrm{C} 20$ & 1.346 & 1.556 \\
\hline H43-H58 & 4.058 & 4.471 \\
\hline $\mathrm{H} 48-\mathrm{H} 58$ & 6.612 & 6.255 \\
\hline H49-H58 & 5.982 & 5.934 \\
\hline Energy (au) & -1359.2686 & -1359.2729 \\
\hline Energy (Kcal/mol) & -852953.828 & -852956.552 \\
\hline$\mu$ (Debye) & 3.9300 & 10.6461 \\
\hline \multicolumn{3}{|c|}{ Bond angle } \\
\hline C53-O55-H56 & 112.8 & 103.1 \\
\hline C18-C20-O21 & 125.0 & 124.8 \\
\hline N41-C39-O40 & 120.5 & 121.2 \\
\hline O54-C53-O56 & 121.6 & 122.2 \\
\hline \multicolumn{3}{|c|}{ Dihedral angle } \\
\hline $\mathrm{H} 23-\mathrm{O} 22-\mathrm{C} 23-\mathrm{O} 24$ & 172.5 & 174.2 \\
\hline O40-C39-C41-C50 & 2.3 & 176.6 \\
\hline O54-C53-O55-C53 & -158.2 & 178.1 \\
\hline O40-H56-O55-C53 & 7.7 & -41.8 \\
\hline O21-H56-O55-C53 & 156.8 & 3.9 \\
\hline \multicolumn{3}{|c|}{ Charge } \\
\hline $\mathrm{O} 40$ & -0.49 & -0.53 \\
\hline H56 & +0.47 & +0.45 \\
\hline O55 & -0.60 & -0.50 \\
\hline $\mathrm{H} 23$ & +0.42 & +0.42 \\
\hline $\mathrm{O} 22$ & -0.55 & -0.56 \\
\hline
\end{tabular}

between O21-H56 atoms $\left(d_{\mathrm{H} 56-\mathrm{O} 21}=1.799 \AA\right)$ in the $s$ cis conformer triggers a modification of the dihedral angle O21-H56-O55-C53 $\left(\phi=156.8^{\circ}\right)$ which may explain the low stability of the cis form. On the other hand, the low interaction between $\mathrm{H} 56-\mathrm{O} 21\left(d_{\mathrm{H} 56-\mathrm{O} 21}=4.816 \AA\right)$ in the $s$ trans conformer yields a change in the dihedral angle $(\phi=$ 3.9) so the atoms $\mathrm{H} 56$ and $\mathrm{O} 40$ were far from each other and the trans was more stable.

It is worth noting that there are two hydrogen bonds, one between atoms H56-O40 and another between H55-O21, but the stability was determined by the first bond because 

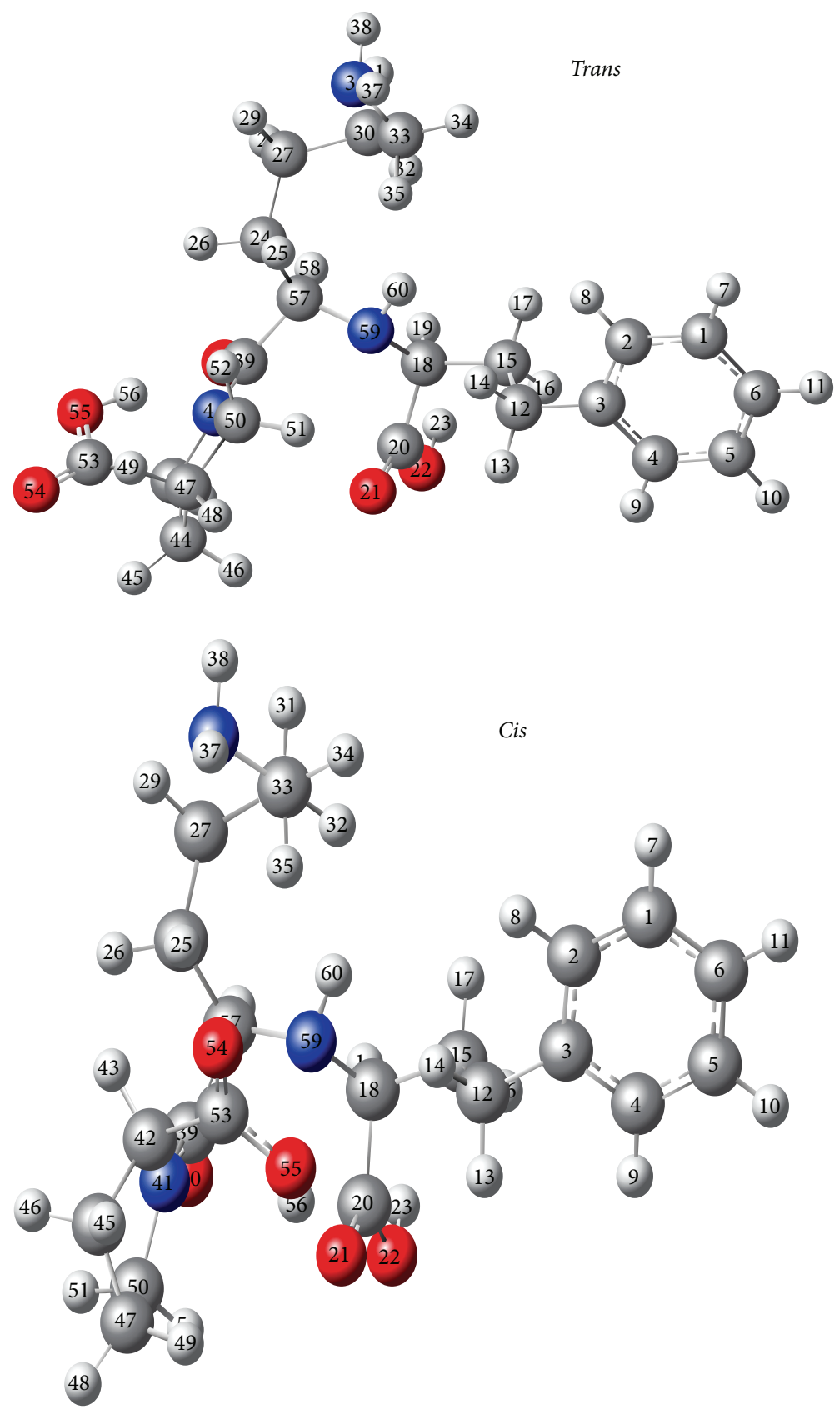

FIgURE 8: DFT/B3LYP optimized geometries of lisinopril.

the distance is shorter $\left(d_{\mathrm{O} 21-\mathrm{H} 56}=1.799 \AA\right)$. In addition, there are strong intramolecular interactions in the trans conformer $(\mu=10.6 \mathrm{D})$ than in the cis form $(\mu=3.9 \mathrm{D})$ indicating a higher stability of the conformer trans.

The distance between the nuclei in both conformers (cis and trans) was compared. It is revealed that in the cis conformer, $\mathrm{H} 43$ is close to $\mathrm{H} 58$ (4.058 $\AA$ ), while $\mathrm{H} 48$ is at a much greater distance from H58 (6.612 $\AA$ ). On the other hand, in the trans conformer $\mathrm{H} 43$ is further away from $\mathrm{H} 58$ (4.471 $\AA$ ), while $\mathrm{H} 48$ is at much greater distance from H58 $(6.225 \AA)$. This is consistent with the results obtained with NOE difference experiments giving an enhancement of $8 \%$ and $21 \%$ in the first irradiation and $34 \%$ and $10 \%$ in the second irradiation.

\section{Conclusions}

Lisinopril exists individually as a mixture of cis-trans isomers in solution. The two isomers could be easily distinguished by HPLC, ${ }^{\mathrm{H}} \mathrm{NMR},{ }^{\mathrm{C}} \mathrm{NMR}$, and ${ }^{1} \mathrm{H}_{-}{ }^{1} \mathrm{H}$ NOE spectra. The results of the various investigations by NMR and those of the theoretical study are in favor of assigning trans form to the major isomer present under the conditions used in the HPLC studies. Additionally, a relative to successful combination of 
molecular modeling studies with experimental spectroscopic assays was used in order to elucidate the molecular bases.

\section{Conflict of Interests}

The authors declare that there is no conflict of interests regarding the publication of this paper.

\section{Acknowledgments}

The authors want to express their special thanks to Dr. M. A. M. K. Sanhoury of the Faculty of Sciences of Tunis for his valuable help and discussion of this work. They also thank the editors and anonymous referees for valuable comments and suggestions that greatly improved the paper.

\section{References}

[1] E. Mutschler, H. Derendorf, K. Schhafer-Korting, K. Elord, and S. Esters, Drug Actions. Basic Principals and Therapeutic Aspects, pp. 385-390, Medpharm Scientific Publishers, Stuttgart, Germany, 1995.

[2] F. Thunecke, A. KLalman, F. Kalmen, S. Ma, A. S. Rathore, and C. Horvath, "Kinetic study on the cis-trans isomerization of peptidyl-proline dipeptides," Journal of Chromatography A, vol. 744, no. 1-2, pp. 259-272, 1996.

[3] J. L. Kofron, P. Kuzmic, E. Colon-Bonilla, and D. H. Rich, "Determination of kinetic constants for peptidyl prolyl cistrans isomerases by an improved spectrophotometric assay," Biochemistry, vol. 30, no. 6127, p. 6134, 1991.

[4] A. Skoglof, I. Nilson, S. Gustaffsson, J. Deinum, and P. Gtithe, "Cis-trans isomerization of an angiotensin I-converting enzyme inhibitor. An enzyme kinetic and nuclear magnetic resonance study," Biochimica et Biophysica Acta, vol. 1041, no. 1, pp. 22-30, 1990.

[5] S. Bouabdallah, H. Trabelsi, T. B. Dhia, S. Sabbah, K. Bouzouita, and R. Khaddar, "RP-HPLC and NMR study of cis-trans isomerization of enalaprilat," Journal of Pharmaceutical and Biomedical Analysis, vol. 31, no. 4, pp. 731-741, 2003.

[6] R. M. Veronika and G. S. Peter, "HPLC-NMR of the conformers of captopril," in Proceedings of the 23rd International Symposium on High Performance Liquid Phase Separations and Related Techniques (HPLC '99), PB12/46, March 1999.

[7] W. R. Melander, J. Jacobson, and C. Horváth, "Effect of molecular structure and conformational change of proline-containing dipeptides in reversed-phase chromatography," Journal of Chromatography A, vol. 234, no. 2, pp. 269-276, 1982.

[8] J. Jacobson, W. Melander, G. Vaisnys, and C. Horváth, "Kinetic study on cis-trans proline isomerization by high-performance liquid chromatography," Journal of Physical Chemistry, vol. 88, no. 20, pp. 4536-4542, 1984.

[9] S. Gustafsson, B.-M. Eriksson, and I. Nilsson, "Multiple peak formation in reversed-phase liquid chromatography of ramipril and ramiprilate," Journal of Chromatography A, vol. 506, pp. 7583, 1990.

[10] R. Hana and A. Wada, "Analysis of the cis-trans isomerization kinetics of 1-alanyl-1-proline by the elution-band relaxation method," Journal of Chromatography A, vol. 394, pp. 273-278, 1987.
[11] S. Bouabdallah, H. Trabelsi, K. Bouzouita, and S. Sabbah, "Reversed-phase liquid chromatography of lisinopril conformers," Journal of Biochemical and Biophysical Methods, vol. 54, pp. 391-405, 2002.

[12] A. Shoji, A. Yanagida, H. Shindo, Y. Ito, and Y. Shibusawa, "Counter-current chromatographic estimation of hydrophobicity of Z-(cis) and E-(trans) enalapril and kinetics of cis-trans isomerization," Journal of Chromatography A, vol. 1157, no. 1-2, pp. 101-107, 2007.

[13] X. Z. Qin, P. Ip, and W. E. Tsai, "Determination and rotamer separation of enalapril maleate by capillary electrophoresis," Journal of Chromatography A, vol. 6626, no. 2, pp. 251-258, 1992.

[14] A. Moore and J. Jorgenson, "Resolution of cis and trans isomers of peptides containing proline using capillary zone electrophoresis," Journal of Analytical Chemistry, vol. 67, no. 19, pp. 3464-3475, 1995.

[15] S. Ma, F. Kalman, A. Kalman, F. Thunecke, and C. Horvath, "Capillary zone electrophoresis at subzero temperatures. I. Separation of the cis and trans conformers of small peptides," Journal of Chromatography A, vol. 716, no. 1-2, pp. 167-182, 1995.

[16] A. S. Rathore and C. Horváth, "Capillary zone electrophoresis of interconverting cis-trans conformers of peptidyl-proline dipeptides: estimation of the kinetic parameters," Electrophoresis, vol. 18, no. 15, pp. 2935-2943, 1997.

[17] A. Christopher, C. A. Evans, and D. L. Rabenstein, "Nuclear magnetic resonance studies of the acid-base chemistry of amino acids and peptides: II. Dependence of acidity of the C-terminal peptide bond," Journal of the American Chemical Society, vol. 96, pp. 7311-7315, 1974.

[18] R. E. London, N. A. Matwiyoff, J. M. Stewart, and J. R. Cann, ${ }^{~}{ }^{13} \mathrm{C}$ nuclear magnetic resonance study of the cis-trans isomerism in X-Pro-Pro tripeptides," The Journal of Biochemistry, vol. 17, no. 12, pp. 2277-2283, 1978.

[19] Z. P. Liu and L. M. Gierash, "Combined use of molecular dynamics simulations and NMR to explore peptide bond isomerization and multiple intramolecular hydrogen-bonding possibilities in a cyclic pentapeptide, cyclo (Gly-Pro-D-PheGly-Val)," Journal of Biopolymers, vol. 32, no. 12, pp. 1727-1739, 1992.

[20] J. Poznanski, A. Ejchart, K. L. Wierzchowski, and M. Ciurak, ${ }^{\circ 1} \mathrm{H}$ - and ${ }^{13} \mathrm{C}$-nmr investigations on cis-trans isomerization of proline peptide bonds and conformation of aromatic side chains in H-Trp-(Pro) ${ }_{n}$-Tyr-OH peptides," Journal of Biopolymers, vol. 33, no. 5, pp. 781-759, 1993.

[21] Y. Sakamoto and T. Ishi, "Conformational studies by ${ }^{1} \mathrm{H}$ and ${ }^{13} \mathrm{C}$ NMR of lisinopril," Journal of Molecular Structure, vol. 198, pp. 129-136, 1993.

[22] A. Saran, S. Srivastava, and E. Coutinho, "Conformation and macromolecular interaction of ACE inhibitors enalapril and lisinopril by NMR," European Journal of Pharmaceutical Sciences, vol. 1, no. 4, pp. 181-188, 1994.

[23] J. N. S. Evans, Biomolecular NMR Spectroscopy, Oxford University Press, 1995.

[24] Q. Teng, Structural Biology: Practical NMR Applications, Springer, 2005.

[25] G. Ivanova, B. Yakimova, S. Angelova, I. Stoineva, and V. Enchev, "Influence of $\mathrm{pH}$ on the cis-trans isomerization of Valine-Proline dipeptide: an integrated NMR and theoretical investigation," Journal of Molecular Structure, vol. 975, pp. 330$334,2010$.

[26] A. A. Isab and M. I. M. Wazeer, "Solid and solution NMR studies of the complexation of $\mathrm{Ag}^{+}$with the trans isomer of captopril: 
biological activities of this high blood pressure drug along with its $\mathrm{Ag}^{+}$complex," Spectrochimica Acta A, vol. 65, no. 1, pp. 191195, 2006.

[27] C. A. Evans and D. L. Rabenstein, "Nuclear magnetic resonance studies of the acid-base chemistry of amino acids and peptides. II. Dependence of the acidity of the C-terminal carboxyl group on the conformation of the C-terminal peptide bond," Journal of the American Chemical Society, vol. 96, no. 23, pp. 7312-7317, 1974.

[28] J. Frisch, G. W. Trucks, H. B. Schlegel et al., Gaussian 03, Revision A. 1, Gaussian, Inc., Pittsburgh, Pa, USA, 2003.

[29] A. D. Becke, "Density-functional thermochemistry. III. The role of exact exchange," The Journal of Chemical Physics, vol. 98, no. 7, p. 5648, 1993.

[30] W. J. Hehere, R. Ditchfield, and J. A. Pople, "Self-consistent molecular-orbital methods XII. Furtherextension of Gaussiantype basis sets for use in molecular orbital studies of organic molecules," The Journal of Chemical Physics, vol. 56, no. 5, p. 2257, 1972.

[31] G. A. Petersson, A. Bennett, T. G. Tensfeldt, M. A. Al-Laham, W. A. Shirley, and J. Mantzaris, "A complete basis set model chemistry. I. The total energies of closed-shell atoms and hydrides of the first-row elements," The Journal of Chemical Physics, vol. 89, no. 4, p. 2193, 1988.

[32] G. A. Petersson and M. A. Al-Laham, "A complete basis set model chemistry. II. Open-shell systems and the total energies of the first-row atoms," The Journal of Chemical Physics, vol. 94, no. 9, p. 6081, 1991.

[33] P. C. Hariharan and J. A. Pople, "The influence of polarization functions on molecular orbital hydrogenation energies," Theoretica Chimica Acta, vol. 28, no. 3, pp. 213-222, 1973.

[34] V. A. Rassolov, M. A. Ratner, J. A. Pople, P. C. Redfern, and L. A. Curtiss, "6-31G* basis set for third-row atoms," Journal of Computational Chemistry, vol. 22, no. 9, pp. 976-984, 2001.

[35] D. E. Henderson and C. Horvath, "Low temperature highperformance liquid chromatography of cis-trans proline dipeptides," Journal of Chromatography A, vol. 368, pp. 203-213, 1986.

[36] D. E. Henderson and J. A. Mello, "Physicochemical studies of biologically active peptides by low-temperature reversedphase high-performance liquid chromatography," Journal of Chromatography A, vol. 499, pp. 79-88, 1990.

[37] P. K. Owens, L. A. Svensson, and J. Vessman, "Direct separation of captopril diastereoisomers including their rotational isomers by RP-LC using a teicoplanin column," Journal of Pharmaceutical and Biomedical Analysis, vol. 25, no. 3-4, pp. 453-464, 2001.

[38] H. Trabelsi, S. Bouabdallah, S. Sabbah, F. Raouafi, and K. Bouzouita, "Study of the cis-trans isomerization of enalapril by reversed-phase liquid chromatography, Journal of Chromatography $A$, vol. 871, no. 1-2, pp. 189-199, 2000.

[39] S. Bouabdallah, H. Trabelsi, M. T. B. Dhia, and N. B. Hamida, "Kinetic study on the isomerization of perindopril by HPLC," Chromatographia, vol. 75, no. 21-22, pp. 1247-1255, 2012.

[40] F. A. Bovey, J. J. Ryan, and F. P. Hood, "Polymer nuclear magnetic resonance spectroscopy. XV. The conformation of polysarcosine," Macromolecules, vol. 1, no. 4, pp. 305-307, 1968.

[41] P. A. Hart and J. P. Davis, "Conformation of nucleosides and nucleotides. Application of the nuclear Overhauser effect," Journal of the American Chemical Society, vol. 91, no. 2, pp. 512$513,1969$.

[42] P. E. Shirmer, J. H. Noggle, J. P. Davis, and P. A. Hart, "Determination of molecular geometry by quantitative application of the nuclear Overhauser effect," Journal of the American Chemical Society, vol. 92, no. 11, pp. 3266-3273, 1970. 

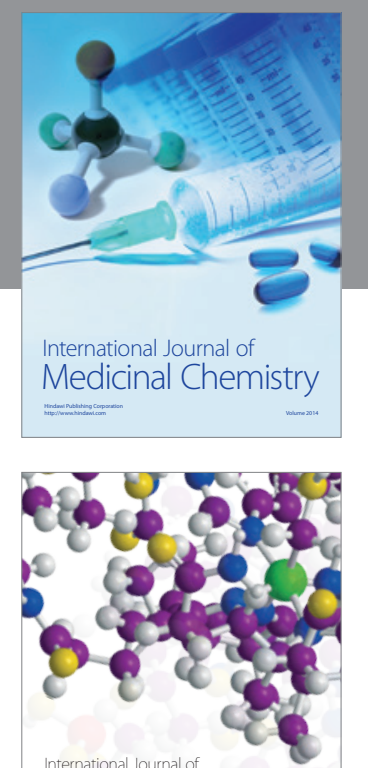

\section{Carbohydrate} Chemistry

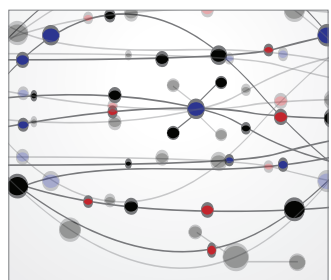

The Scientific World Journal
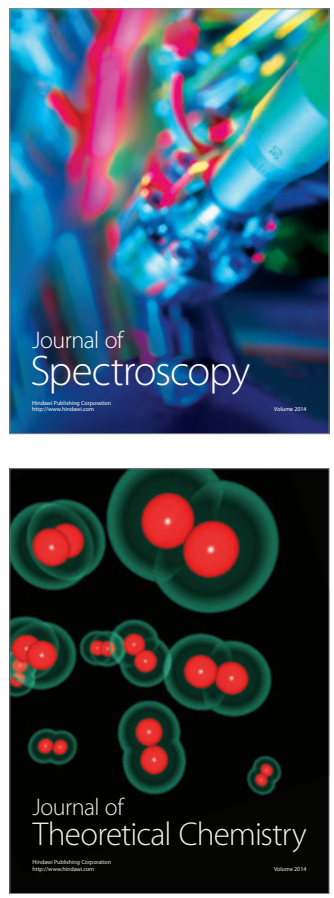
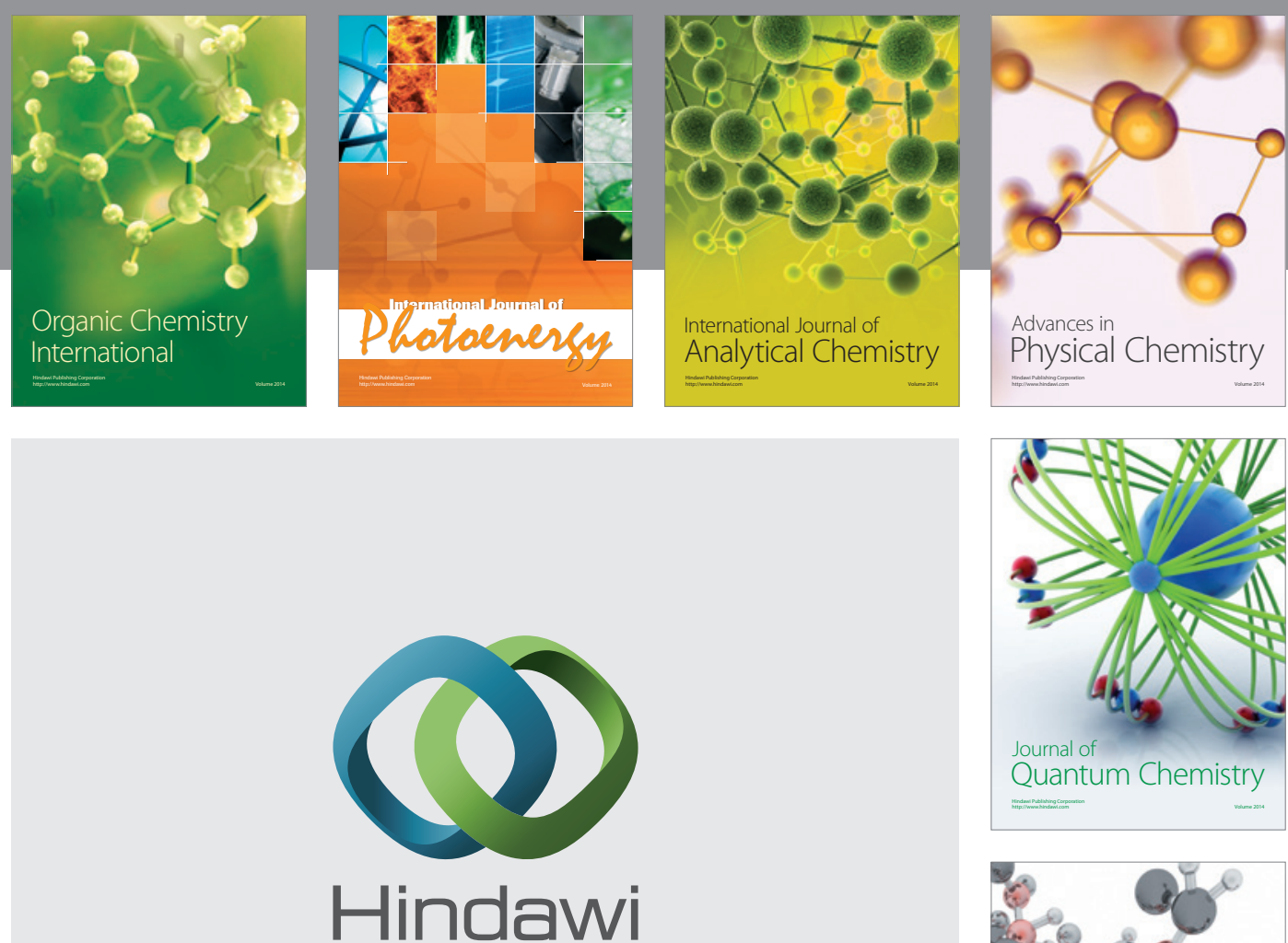

Submit your manuscripts at

http://www.hindawi.com

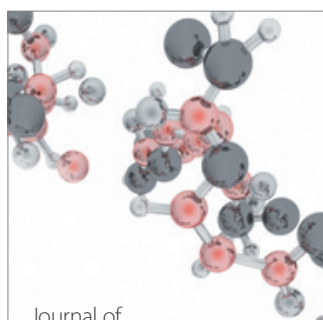

Analytical Methods

in Chemistry

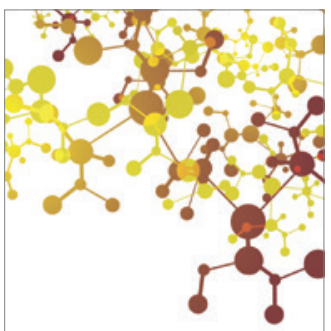

Journal of

Applied Chemistry

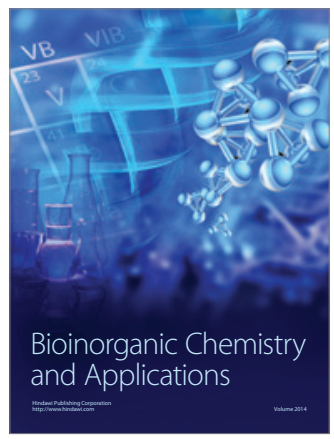

Inorganic Chemistry
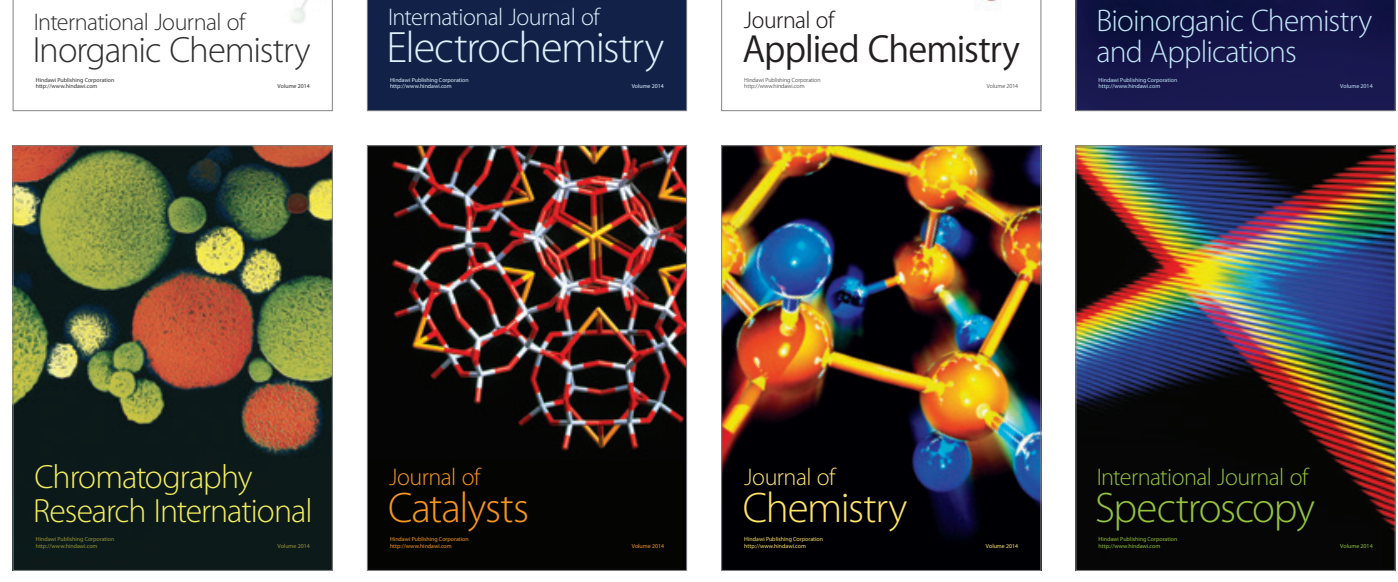